Taeshin Kim, Bum-Joon Kim,

Se-Hoon Kim, Seung-Hwan Lee

Department of Neurosurgery, Korea University Ansan Hospital, Ansan, Korea

\section{Corresponding Author:}

Bum-Joon Kim

Department of Neurosurgery, Korea University Ansan Hospital, 123 Jeokgeum-ro, Danwon-gu, Ansan 15355, Korea

Tel: +82-31-412-5053

Fax: +82-31-412-5054

E-mail: nsbjkim@gmail.com

Received: April 5, 2017

Revised: May 29, 2017

Accepted: June 5, 2017
Copyright (C 2017 by The Korean Spinal Neurosurgery Society

This is an open access article distributed under the terms of the Creative Commons Attribution Non-Commercial License (http://creativecommons.org/licenses/bync/4.0/) which permits unrestricted noncommercial use, distribution, and reproduction in any medium, provided the original work is properly cited.

\title{
Tophaceous Gout in the Lumbar Spinal Canal Mimicking Epidural Spinal Tumor
}

Gout is an inflammatory arthritis characterized by deposition of monosodium urate crystals in joints. Though gout frequently involves the big toe or other extremities, it rarely occurs in the spinal canal. A 35-year-old man presented with left L5 radiculopathy. He had leg pain for 8 months and received several epidural steroid injections. Magnetic resonance imaging revealed a $1.7 \times 1.1-\mathrm{cm}$ ovoid contrast-enhancing mass, causing pressure erosion of the left $L 5$ pedicle. Microscopic laminotomy was performed at the left L5 lamina. White chalky materials, identified at the left lateral recess of the spinal canal, were removed in a piecemeal manner. The histopathologic diagnosis was tophaceous gout. Although the patient's radiating pain did not resolve postoperatively, it was dramatically relieved with uric acid-lowering medications. If a mass effect is suspected, surgical removal of gouty tophi might aid in symptom release and definite diagnosis. Medical treatment after rheumatology consultation is crucial.

Key Words: Gouty arthritis, Hyperuricemia, Uric acd, Spinal canal, Zygapophyseal joint, Radiculopathy

\section{INTRODUCTION}

Gout refers to an inflammatory arthritis characterized by "tophi," which are monosodium urate crystal deposits in the synovium ${ }^{8)}$. Crystallization is caused by poor solubility of the synovial fluid compared to the plasma and the lower temperatures exacerbate the phenomenon; hence, gout usually involves the peripheral joints ${ }^{8,12}$. However, in rare cases, gouty tophi involve the axial joints including the spine $^{4,8,11,12,18)}$. The reported spinal gout cases present similar clinical manifestations as other spinal diseases, including back/neck pain, radiculopathy, and myelopathy ${ }^{3,4)}$.

During the past 2 decades, the prevalence of gout has increased about 2 fold owing to the increased purine-rich diet ${ }^{6,11,16)}$. However, the exact prevalence and pathophysiology of spinal gout is still unclear because of its uncommonness. In many cases, the radiologic features of spinal gout mimic other spinal diseases ${ }^{2,4,14,17}$, which makes early detection and treatment difficult.

We present a case of tophaceous gout mimicking tumor in the spinal canal and review of the literature.

\section{CASE REPORT}

A 35-year-old male patient was hospitalized due to radiating pain and paresthesia along the left L5 dermatome. His symptoms started 8 months before; although he had received several epidural steroid injections at other clinics, his pain continuously aggravated. The physical examination revealed that, the straight leg raising (SLR) test was positive at $45^{\circ}$, and the crossed SLR test was positive at $60^{\circ}$. The patient did not show any pain or swelling in the joints of his extremities. He had no motor weakness and showed no significant underlying diseases except hypertension. Magnetic resonance imaging (MRI) revealed a $1.7 \times 1.1-\mathrm{cm}$ ovoid extradural mass-like lesion in the left L4/5 subarticular zone. It showed low signal intensity on both T1- and T2-weighted images and was heterogeneously well enhanced with gadolinium (Fig. 1). Computed tomography (CT) showed pressure erosion at the medial aspect of the left L5 pedicle, and "punch-out" erosions with soft tissue swelling were also found at the left facet joint (Fig. 2). Simple radiographs of the lumbar spine showed spondylolysis on the L5 pars interarticularis bilaterally.

The patient was underwent decompressive surgery. A laminotomy on the left upper portion of the L5 lamina revealed whitish chalky materials at the medial aspect of the left $\mathrm{L} 5$ pedicle, which severely compressed the nerve root at the shoulder portion (Fig. 3). There was no definite capsule, and the frozen histopathologic report was "crystal deposition." After the 

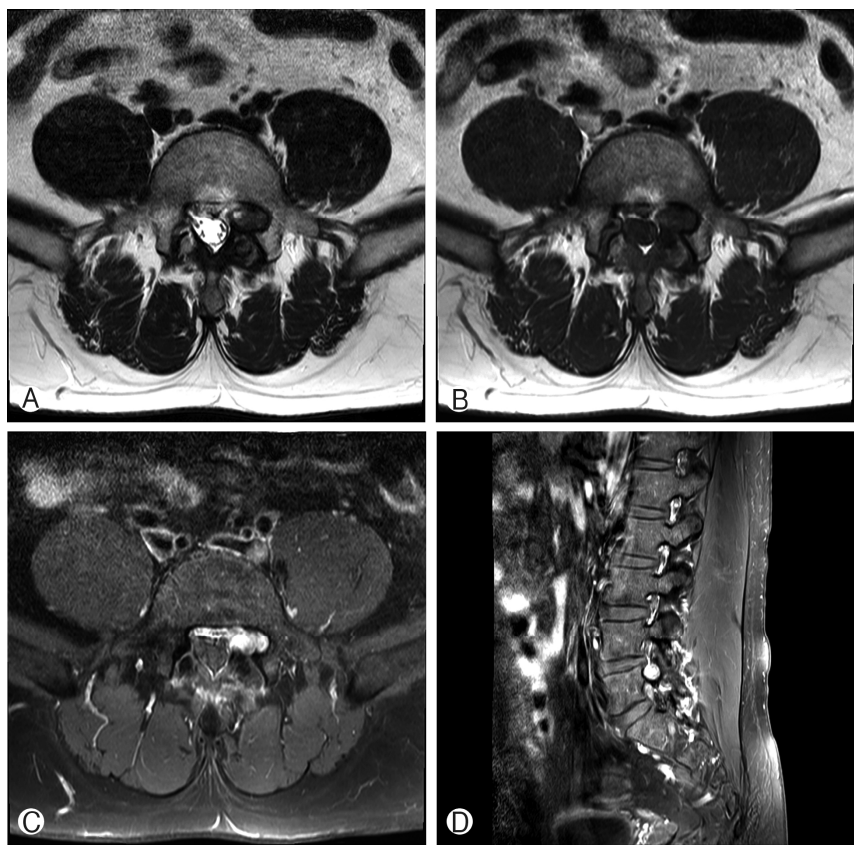

Fig. 1. Magnetic resonance imaging shows $1.7 \times 1.1-\mathrm{cm}$ ovoid extradural mass at the left L4/5 subarticular area, with low signal intensity on T2- (A) and T1-weighted images (B). (C, D) The mass shows strong enhancement with gadolinium contrast.

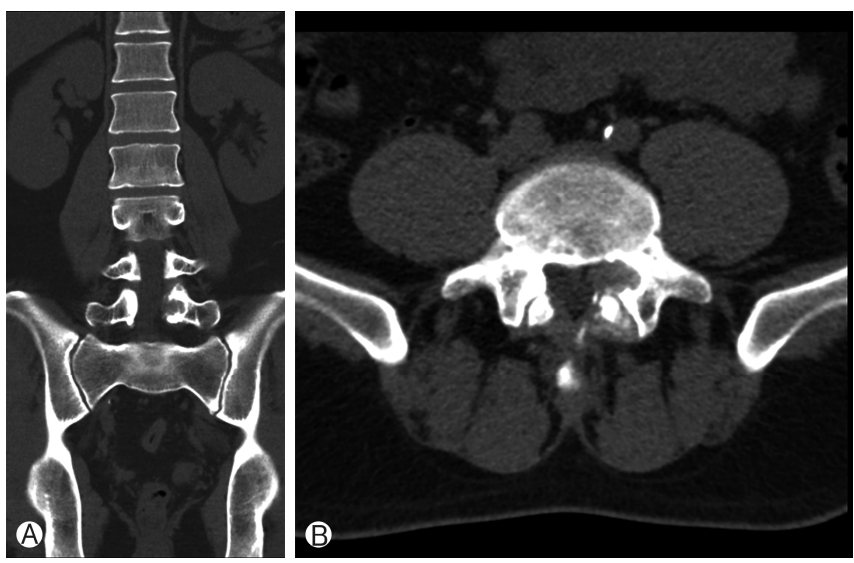

Fig. 2. Computed tomography shows pressure erosion of the left L5 pedicle (A) with punch-out erosions and soft tissue swelling at the left facet joint (B).
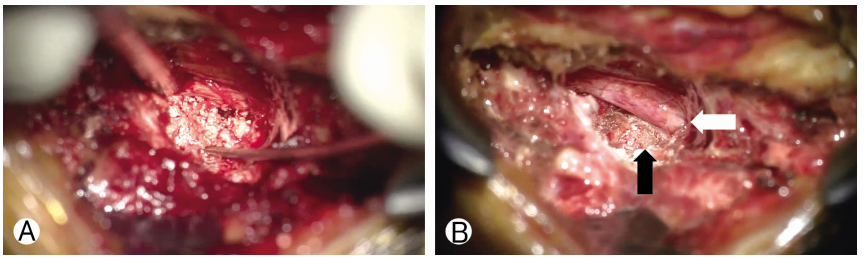

Fig. 3. (A) During the surgery, white chalky materials were identified at the shoulder region of the left L5 nerve root. (B) After removal of the tophi, the eroded left L5 pedicle with smooth surface (black arrow) and decompressed nerve root (white arrow) appeared.

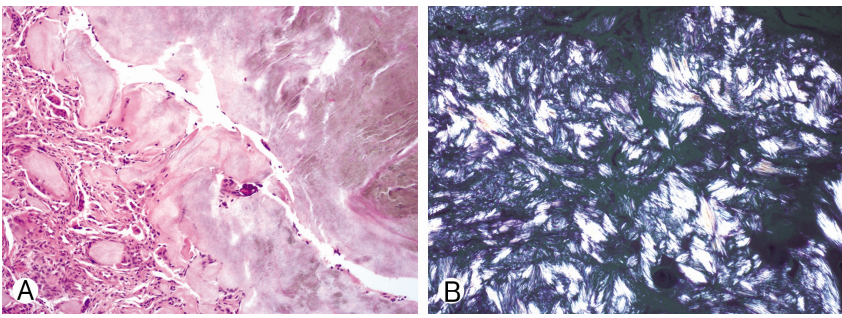

Fig. 4. (A) Extradural lesion comprises abundant deposited crystals surrounded by a foreign body-type giant cell reaction $(\mathrm{H} \& \mathrm{E}, \times 200)$. (B) Numerous needle-shaped negatively birefringent monosodium urate crystals were identified using polarized light microscopy $(\times 400)$.

gross complete removal of the material, the left L5 nerve root was completely decompressed (Fig. 3). The final histopathologic finding showed numerous needle-shaped monosodium urate crystals (Fig. 4), which was consistent with tophaceous gout. Postoperatively, the patient presented aggravated radiating pain. With the guidance of rheumatologists, colchicine and febuxostat were administrated. After 3 days of medication, the symptom resolved dramatically.

\section{DISCUSSION}

Gout in the spinal canal is difficult to diagnose because it is extremely rare; its clinical manifestation and radiologic findings mimic tumor, abscess, tuberculosis, and degenerative spinal diseases $^{2,4,14,17}$. In the present case, our initial impression was epidural spinal tumor because the ovoid enhancing mass showed pressure erosion of the pedicle. Therefore, a meticulous review of the previous studies is very important for clinicians. Although gouty tophi show various patterns, MRI is still the most important tool of diagnosis. Elgafy et al. ${ }^{4)}$, in their systematic review, reported that the majority of spinal gout tophi were hypointense on both T1- and T2-weighted images (45.5\% and 26.5\%, respectively), and $47.1 \%$ of them showed gadolinium enhancement. The contrast enhancement of tophi is known to be a result of the vascularized reactive granulation formation ${ }^{6,8,19)}$. In our case, the tophi were hypointense on both T1- and T2-weighted images, and the gadolinium study showed enhancement of the tophi and soft tissues around the facet joints (Fig. 1). Although CT is inferior to MRI in differentiating the neural structures and soft tissue, it is very helpful in the diagnosis of spinal gout because the tiny erosions caused by tophi are more distinctly visualized on $\mathrm{CT}^{4,8)}$. In our case, remarkable "punched-out" patterned erosions were identified at L4/5 and L5/S1 facet joints.

Based on the previous studies, gouty attacks are not always related to the serum uric acid level; only a small percentage of patients with hyperuricemia develop gout, and about 30\% of patients with gout have normal serum uric acid level ${ }^{7,14,17)}$. In many spinal gout cases, the laboratory finding shows elevated serum uric acid level of above $7.0 \mathrm{mg} / \mathrm{dL}^{4,7,14}$. Our patient also showed elevated serum uric acid level of $10.4 \mathrm{mg} / \mathrm{dL}$. Inflammatory markers such as erythrocyte sedimentation rate and C-reac- 
tive protein were within the normal range. We suggest that if there is an extradural mass with surrounding bony erosions, hyperuricemia can be a strong diagnostic clue.

The most commonly affected level of the spinal gout is the lumbar level followed by the cervical and thoracic levels ${ }^{5,8,11)}$. This incidence can be explained by the pathogenesis of gout, the location of which is related to the solubility of crystals $^{10,12,13)}$. The low temperature and avascular tissues can decrease the solubility of urate crystals; hence, gout commonly occurs in locations with these conditions ${ }^{10,12,13)}$. Spinal gout can show various concomitant degenerative features, and it has been suggested that factors such as degenerative disease of the spine, tissue necrosis, or spinal injury trigger the process ${ }^{1,3,10}$. Here, the patient had spondylolysis at the pars interarticularis of L5 bilaterally. In our opinion, this finding implies that the degenerative spondylolysis worsened the solubility of urate crystals at the synovium of the adjacent facet joints and triggered tophi deposit.

Pharmacotherapy is the mainstay of the treatment for gout, which causes the dissolution of monosodium urate crystals by lowering the serum urate level ${ }^{15)}$. Nonsteroidal anti-inflammatory drugs (NSAIDs), colchicine, and xanthine oxidase inhibitors, such as allopurinol and febuxostat, are the key drugs ${ }^{4,16}$. We applied NSAIDs postoperatively; however, the symptoms did not improve. After consultation with a rheumatologist, we added colchicine with febuxostat. After 3 days of medications, the patient's radiating pain dramatically subsided. We recommend starting the pharmacologic approach early with surgery when spinal gout is diagnosed.

Although the role of surgery in spinal gout is still not established yet, there is agreement that decompression and excision of the tophi are necessary for patients with neurologic complications or severe joint damage ${ }^{4,9}$. Since it is difficult to identify a gouty tophi without histologic study in many spinal gout cases ${ }^{2}$, surgical intervention is needed for final diagnosis. In our case, the patient underwent surgery because he presented intractable radiating pain and radiologic studies revealed damage in the pedicle and facet joints. We suggest that early surgical removal of the tophi can prevent further damage to the spinal joints and can reduce the need for additional spinal instrumentation. Furthermore, the typical intraoperative findings should help clinicians administer appropriate pharmacotherapy in a timely manner.

\section{CONCLUSION}

Gout tophi in the spinal canal are rare. Even though it is difficult to differentiate, the main treatment is decompressive surgery when presented with neurologic deficits. Pharmacotherapy associated with ordinary gout should be accompanied with surgical treatment because surgical treatment alone cannot resolve all the symptoms, and gout can recur when hyperuricemia is not suppressed.

\section{CONFLICT OF INTEREST}

No potential conflict of interest relevant to this article was reported.

\section{REFERENCES}

1. Beier CP, Hartmann A, Woertgen C, Brawanski A, Rothoerl RD: A large, erosive intraspinal and paravertebral gout tophus. Case report. J Neurosurg Spine 3:485-487, 2005

2. Bonaldi VM, Duong H, Starr MR, Sarazin L, Richardson J: Tophaceous gout of the lumbar spine mimicking an epidural abscess: MR features. AJNR Am J Neuroradiol 17:1949-1952, 1996

3. Draganescu M, Leventhal LJ: Spinal gout: case report and review of the literature. J Clin Rheumatol 10:74-79, 2004

4. Elgafy H, Liu X, Herron J: Spinal gout: a review with case illustration. World J Orthop 7:766-775, 2016

5. Fenton P, Young S, Prutis K: Gout of the spine. Two case reports and a review of the literature. J Bone Joint Surg Am 77:767-771, 1995

6. Girish G, Melville DM, Kaeley GS, Brandon CJ, Goyal JR, Jacobson JA, et al: Imaging appearances in gout. Arthritis 2013: 673401, 2013

7. Hasturk AE, Basmaci M, Canbay S, Vural C, Erten F: Spinal gout tophus: a very rare cause of radiculopathy. Eur Spine J 21 Suppl 4:S400-403, 2012

8. Jegapragasan M, Calniquer A, Hwang WD, Nguyen QT, Child Z: A case of tophaceous gout in the lumbar spine: a review of the literature and treatment recommendations. Evid Based Spine Care J 5:52-56, 2014

9. Kasper IR, Juriga MD, Giurini JM, Shmerling RH: Treatment of tophaceous gout: when medication is not enough. Semin Arthritis Rheum 45:669-674, 2016

10. King JC, Nicholas C: Gouty arthropathy of the lumbar spine: a case report and review of the literature. Spine (Phila Pa 1976) 22: 2309-2312, 1997

11. Konatalapalli RM, Demarco PJ, Jelinek JS, Murphey M, Gibson $\mathrm{M}$, Jennings $\mathrm{B}$, et al: Gout in the axial skeleton. J Rheumatol 36:609-613, 2009

12. Lam HY, Cheung KY, Law SW, Fung KY: Crystal arthropathy of the lumbar spine: a report of 4 cases. J Orthop Surg (Hong Kong) 15:94-101, 2007

13. Mahmud T, Basu D, Dyson PH: Crystal arthropathy of the lumbar spine: a series of six cases and a review of the literature. $J$ Bone Joint Surg Br 87:513-517, 2005

14. Nakajima A, Kato Y, Yamanaka H, Ito T, Kamatani N: Spinal tophaceous gout mimicking a spinal tumor. J Rheumatol 31:1459-1460, 2004

15. Robinson PC, Dalbeth N: Advances in pharmacotherapy for the treatment of gout. Expert Opin Pharmacother 16:533-546, 2015

16. Rymal E, Rizzolo D: Gout: a comprehensive review. JAAPA 27:26-31, 2014

17. Suk KS, Kim KT, Lee SH, Park SW, Park YK: Tophaceous gout of the lumbar spine mimicking pyogenic discitis. Spine J 7:94-99, 2007

18. Yoon JW, Park KB, Park H, Kang DH, Lee CH, Hwang SH, et al: Tophaceous gout of the spine causing neural compression. Korean J Spine 10:185-188, 2013

19. Yu JS, Chung C, Recht M, Dailiana T, Jurdi R: MR imaging of tophaceous gout. AJR Am J Roentgenol 168:523-527, 1997 